\title{
Septins are essential for protrusion and detachment in collective border cell migration
}

\author{
Allison M. Gabbert ${ }^{a}$, James A. Mondo ${ }^{a}$, Joseph P. Campanale ${ }^{a}$, Denise J. Montella,1 \\ a Author info 1 Molecular, Cellular, and Developmental Biology Department at University of California, Santa Barbara \\ ${ }^{1}$ Correspondence: dmontell@ucsb.edu, University of California, Santa Barbara CA 93106
}

\begin{abstract}
Collective cell migration is prevalent throughout development and common in metastatic tumors, yet this process is not fully understood. In this study, we explore the role of septins (Sep) in collective cell migration, using the Drosophila border cell model. We show that Sep2 and Pnut are expressed in migrating border cells and Sep1, 2, 4, and Peanut (Pnut) are required for migration. Pnut stability depends on the expression of Sep1 and Sep2 in epithelial follicle cells and migratory border cells. We show that knockdown of septins prevents normal protrusion and detachment behaviors. High resolution Airyscan imaging reveals Pnut localization in rings at the base of protrusions. While septins function independently of $\mathrm{Cdc} 42$, they colocalize dynamically with nonmuscle myosin II. We suggest that septin polymers may stabilize growing protrusions until sufficient myosin is recruited to retract them.
\end{abstract}

\section{Introduction}

Cell migration is essential for development, wound healing, immune responses, and tumor metastasis. While our fundamental understanding of the molecular mechanisms controlling cell motility derives primarily from studying cells migrating individually on glass, in vivo cells frequently move collectively, i.e. in interconnected groups. In vivo, many cells also move through complex, cell-rich microenvironments that are difficult if not impossible to recapitulate in vitro. Therefore, in vivo models amenable to genetic analysis and live imaging are important.

Border cells in the Drosophila egg chamber provide an excellent model to study collective cell migration (Montell, 2003; Montell et al., 2012). The border cell cluster is made up of four to six migratory cells that surround and transport two non-motile polar cells from the anterior end of the egg chamber to the oocyte during oogenesis (Montell 2012). Cytoskeletal dynamics are critical determinants of cell shape and movement in general and border cells in particular, where the in vivo requirement for the small GTPase Rac in F-actin-rich protrusion and migration was first demonstrated (Murphy and Montell, 1996).

F-actin, microtubules, and intermediate filaments are well-studied, dynamic polymers that contribute to cell shape and motility (Seetharaman and Etienne-Manneville, 2020). Septins are filamentforming GTPases that have been described as a fourth major cytoskeletal element (Mostowy and Cossart, 2012). First discovered as a key component required for budding in S. cerevisiae (Hartwell, 1971), septins are now known to be conserved throughout animals and fungi where they commonly localize to the cell cortex and act as protein scaffolds to regulate cell polarity and cytokinesis amongst other processes (Oh and $\mathrm{Bi}, 2011)$.

Individual septin monomers contain a proline-rich amino-terminal region, a central core that includes a GTP-binding domain, and a carboxyterminal region (Figure 1A). Septins oligomerize via interactions between the GTP-binding domains (G-G) and through the interactions between N- and C-termini of different subunits (N-C) (Figure 1B). Septin polymers can form filaments, bundles, and ring structures (Figure 1C) that can scaffold F-actin or microtubules and associate with cell membranes where they recognize micron-scale curvature (Bridges, et. al 2016). The septin field has rapidly expanded in the last decade, with discoveries that septins are involved in a myriad of processes including cytokinesis, actin bending and organization (Kinoshita, et. al 1997; Kinoshita, et. al 2002), cortical rigidity (Tooley, et. al 2009), and neuronal migration (Shinoda, et. al 2010), to name a few.

The human genome contains 13 different septin genes, mutations in which are associated with multiple diseases including leukemias, solid tumor cancers, and neurological disorders such as Parkinson's disease (Peterson and Petty, 2010). Fruit flies have a simplified set of five septins, Sep1, Sep2, Pnut, Sep4 and Sep5, where Sep1, Sep2, and Pnut have been purified as a complex (Field et. al, 1996). Drosophila and human septins show between 55 and $73 \%$ amino acid sequence identity (Supplemental Figure 1). Drosophila septins are involved in key processes in development such as actomyosin ring closure during embryo cleavage (Xue and Sokac, 2016) and dorsal closure after gastrulation (Fares et. al, 1995); null mutations in Pnut are lethal (Neufeld and Rubin, 1994). Pnut is also expressed in germline and somatic cells of Drosophila ovaries (Akhmetova, et. al 2015), and loss of Sep2 results in sterility (O'Neill and Clark, 2013; O'Neill and Clark, 2016). Septin localization and function in border cells has not yet been reported.

There is a growing appreciation that septins participate in a multitude of cellular processes, yet their molecular mechanisms remain relatively poorly understood compared to F-actin, microtubules, and intermediate filaments. In a microarray analysis, we previously found that Septin 1 (Sep1) and Septin 2 (Sep2) are enriched in migratory cells in the Drosophila egg chamber (Wang, et. al 2006). Here, we report the requirement, localization, and potential role of septins in collective, cooperative, cell-on-cell migration of border cells during Drosophila oogenesis.

\section{$\underline{\text { Results }}$}

Drosophila egg chambers are composed of 16 germline cells - 15 polyploid nurse cells and one oocyte - and $\sim 850$ somatic follicle cells (Figure 1D-F). Border cells develop at the anterior end of the egg chamber and during stage 9 extend protrusions between the nurse cells, delaminate from the epithelium, and migrate down the central path until they reach the oocyte (Fig. 1D-F). To probe the expression and localization of septins in border cells, we stained egg chambers from flies 
bioRxiv preprint doi: https://doi.org/10.1101/2021.04.08.439079; this version posted April 10, 2021. The copyright holder for this preprint (which was not certified by peer review) is the author/funder, who has granted bioRxiv a license to display the preprint in perpetuity. It is made available under aCC-BY 4.0 International license.

Gabbert et al., 08 Apr 2021 - preprint copy - BioRxiv

expressing endogenously tagged Sep2::GFP and stained for Pnut. Pnut and Sep2 were expressed in all follicle cells (Figure 1D-F), including border cells throughout their migration (Figure 1D'-F" and Supplemental Figure 2A and D).

Septin subunits interact with each other at their NC and GG interfaces (Figure 1B) to form complex structures such as filament bundles, and rings (Figure 1C). High resolution Airyscan confocal imaging revealed that Pnut and Sep2 significantly co-localized in the border cell cluster (Figure 1, D-I) with a Pearson's correlation coefficient of 0.8 (Figure 1, H-I). Septins did not colocalize as extensively with F-actin (Person's correlation coefficient $\sim 0.2$ ). These results are consistent with the known interactions between Sep1, Sep2, and Pnut, which have been purified as a complex (Field, et. al 1996).

To test if septins are required for border cell migration, we knocked down each of the five Drosophila septins by driving RNAi expression in all

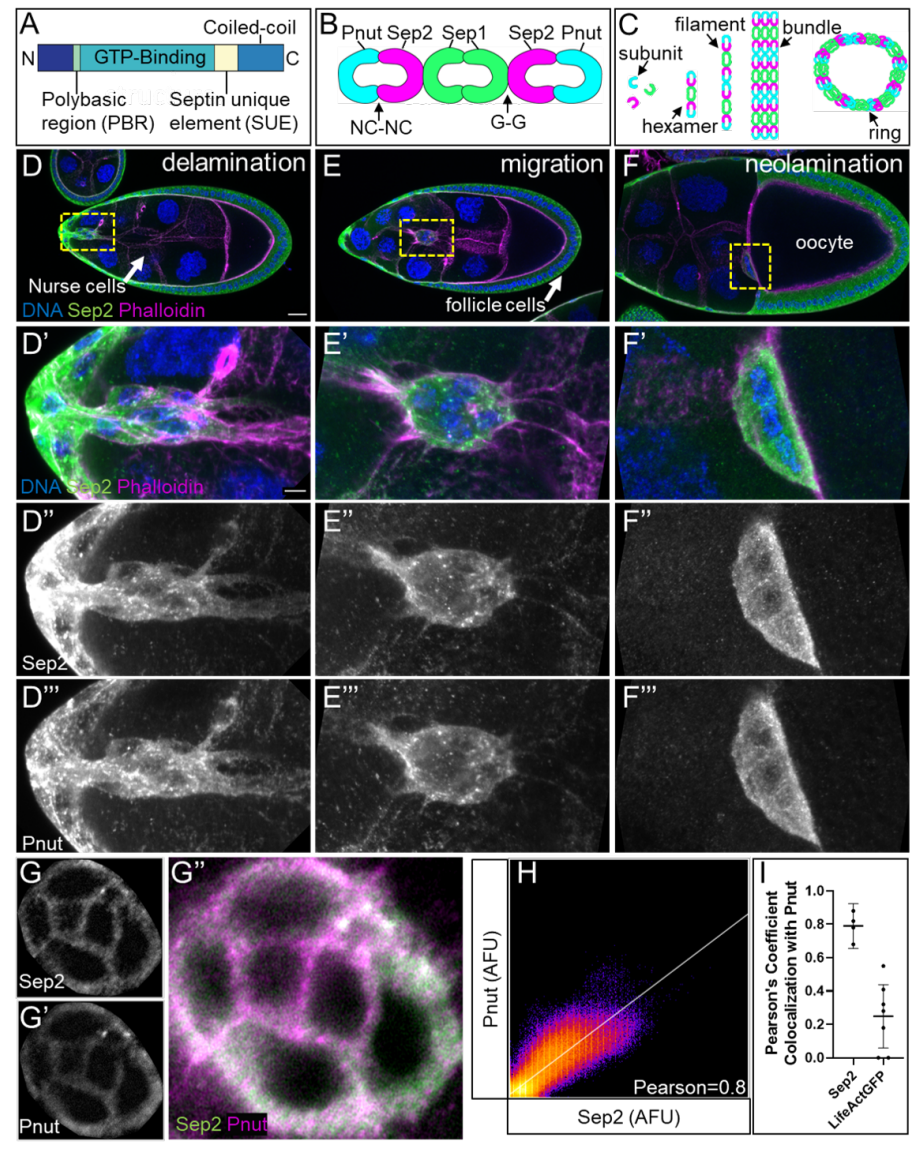

Figure 1. Septin family proteins co-assemble into filaments and are expressed during collective border cell migration. (A) Schematic of septin domains. (B) Septin subunits assemble into complexes through interactions between their NC and G-G interfaces. In Drosophila, Pnut, Sep2, and Sep1 form a complex as shown. (C) Septin subunits can form higher order structures. (D-F) Max intensity projections of egg chambers (D-F) and the respective border cell clusters (D'-F') labeled with Hoechst (blue) and E-cadherin (magenta) and expressing LifeActGFP (green). (D"F'") Separate channels from D'-F' showing Sep2 (D"-F") and Pnut (D'"F"'). (G-G") A single slice of a border cell cluster labeled with Pnut $(G)$, Sep2 (G'), or both (G'). (H-I) Pnut and Sep2 co-localize in border cells with a Pearson's coefficient of 0.8 , compared to LifeActGFP as a control. The scalebar in D is $20 \mu \mathrm{m}$ and $5 \mu \mathrm{m}$ in D'-F". cells of the cluster using c306Gal4. Multiple RNAi lines for each septin impaired border cell migration (Figure 2 and Supplemental Figure 3A). We selected the strongest RNAi line for each of the five septins for further experiments. Two Sep2 loss-of-function mutant alleles also caused border cell migration defects in trans-heterozygous combination (Supplemental figure 3B), confirming the Sep2 RNAi results. However, Sep5 mutants did not show a border cell migration defect (Supplemental figure 3B). Sep2 and Sep5 arose from a recent gene duplication and have some redundant and some non-redundant functions ( $\mathrm{O}^{\prime} \mathrm{Neill}$ and Clark, 2013; O'Neill and Clark, 2016). RNAi constructs against Sep5 that impaired migration were $80 \%$ identical to the corresponding Sep2 nucleotide sequence, and resulted in off-target knockdown of Sep2 (Supplemental Figure 3, C-E). The constructs specifically targeting Sep5 did not significantly impact migration (Supplemental Figure 3A and D). Taken together, we conclude that Sep1, Sep2, Pnut, and Sep4 are required for border cell migration.

The border cell cluster is composed of two, central, non-motile polar cells that secrete the cytokine Unpaired (Upd), which activates Jak/STAT signaling in the surrounding cells (Silver and Montell, 2001; Xi et. al, 2003; Silver et. al, 2005). Jak/STAT is necessary and sufficient to endow anterior follicle cells with the ability to migrate. The outer, migratory border cells then surround and carry the polar cells to the oocyte where both cell types cooperate to build the micropyle (Montell et al., 1992; Edwards et al., 1997; Miao et. al, 2020), the eggshell structure through which sperm enters. To assess the requirement for septins in motile border cells versus non-motile polar cells, we used cell type-specific Gal4 drivers to express Sep RNAi lines. c306Gal4, drives strong expression in anterior and posterior follicle cells, with somewhat weaker expression in

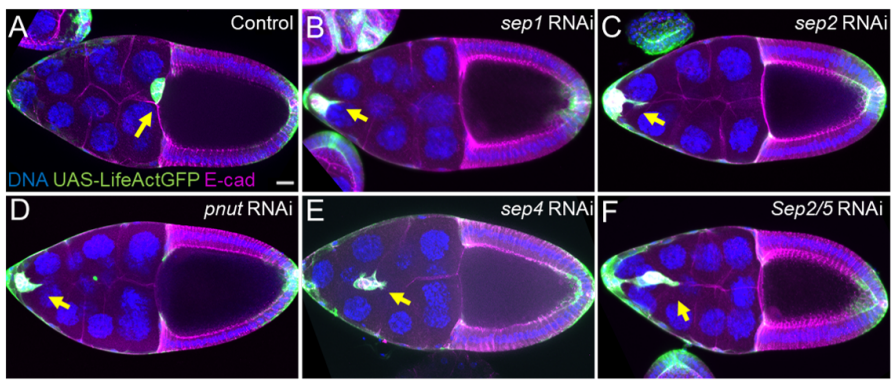

G

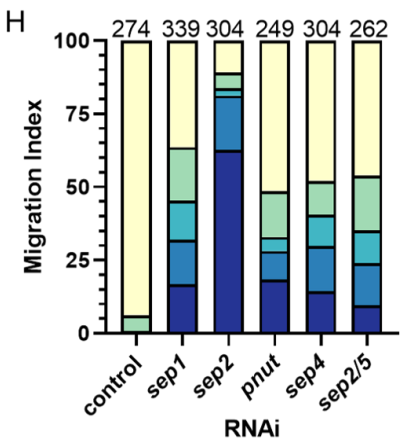

Figure 2. Border cell migration requires Septin expression. (A-F) Max intensity projections of stage 10 egg chambers expressing whiteRNAi (control) or septin RNAi and LifeActGFP in the border cell cluster, labeled with Hoechst (blue) and E-cadherin (magenta). (G) Schematic diagram of a stage 10 egg chamber. Colors indicate how far border cells have migrated as a percentage of the migration path. 100 indicates complete migration. $(\mathrm{H})$ Quantification of border cell migration in egg chambers with RNAi knockdown of the indicated septins. The control was whiteRNAi. The scale bar in A represents $20 \mu \mathrm{m}$ and applies to A-F. 
bioRxiv preprint doi: https://doi.org/10.1101/2021.04.08.439079; this version posted April 10, 2021. The copyright holder for this preprint (which was not certified by peer review) is the author/funder, who has granted bioRxiv a license to display the preprint in perpetuity. It is made available under aCC-BY 4.0 International license.

Gabbert et al., 08 Apr 2021 - preprint copy - BioRxiv

polar cells than in border cells (Fig. 2A-F). Fruitless (Fru) Gal4 is expressed in border and posterior follicle cells but not polar cells, and UpdGal4 is expressed specifically in polar cells. (Supplemental Figure 4). FruGal4-driven RNAi against septins in the border cells resulted in mild impairments of migration whereas knockdown in the polar cells alone with UpdGal4 had no detectable effect (Supplemental Figure 4D). Anti-Pnut antibody staining confirmed more complete knockdown of Pnut with c306Gal4 (Supplemental Figure 4K') than with FruGal4 (Supplemental Figure 4I'), likely accounting for the milder migration defect. By contrast, posterior polar cells showed a comparable knockdown of Pnut protein levels using UpdGal4 and c306Gal4, showing that both were effective (Supplemental Figure 4M'). We conclude that septins are primarily required in the border cells rather than the polar cells to promote migration.

Septins assemble into heteromeric complexes in many contexts (Dolat et. al, 2014; Woods and Gladfelter, 2020), and loss of a single septin can
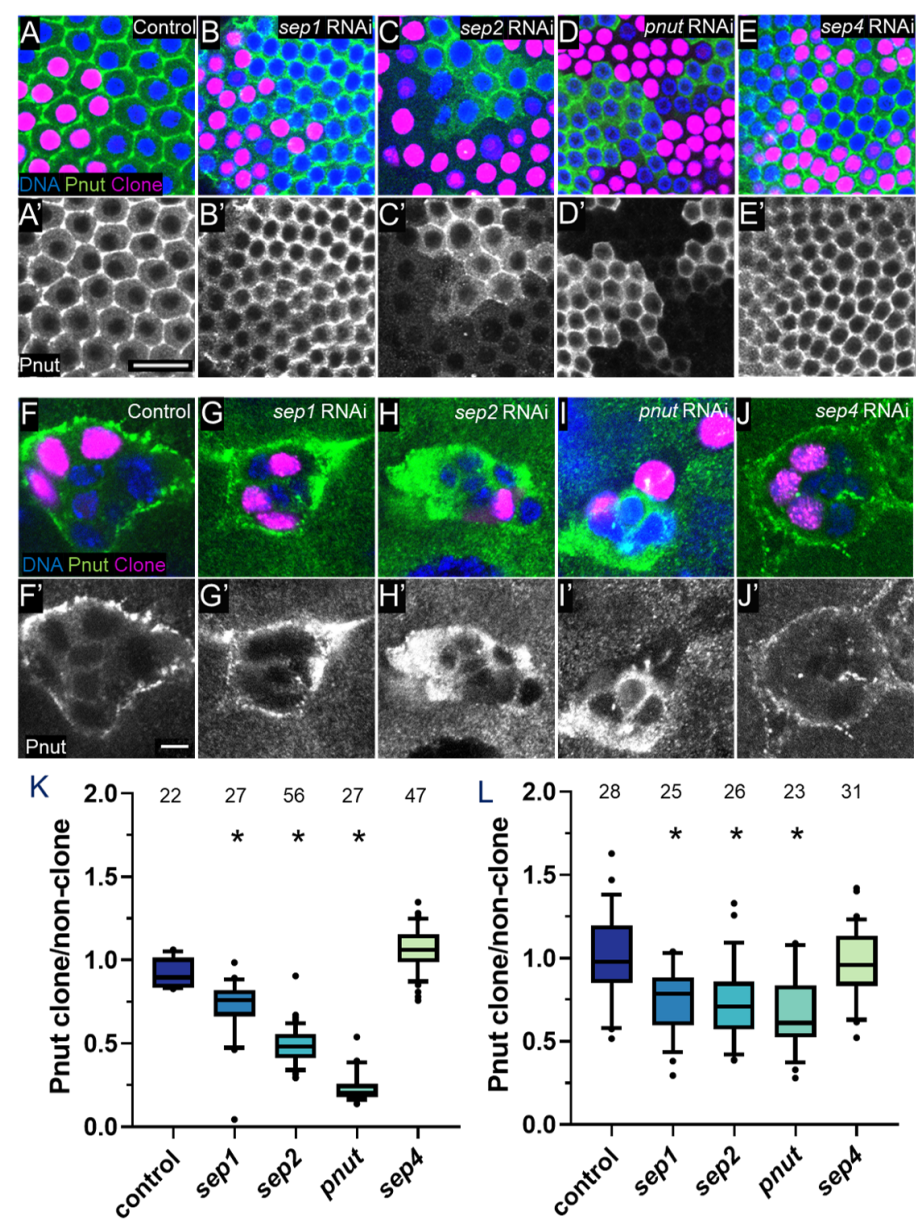

Figure 3. Pnut expression depends on the expression of other septins. (A-E) Single slice images of epithelial follicle cells on the basal surface of the egg chamber expressing whiteRNAi (control) or septin RNAi labeled with Hoechst (blue) and Pnut (green). Clones are marked with magenta nuclei, expressing nuclear-localized RedStinger. (A'-E') Same images from A-E but only labeled with Pnut (gray). (F-J) Single slice images of border cell clusters expressing whiteRNAi (control) or septin RNAi labeled with Hoechst (blue) and Pnut (green). Clones are marked with magenta nuclei, expressing nuclear-localized RedStinger. (K) Quantification of Pnut intensity in follicle cell clones compared to follicle cell non-clones. (L) Quantification of Pnut intensity in border cell clones compared to border cell non-clones. The scalebar in $A^{\prime}$ is $20 \mu \mathrm{m}$ and the scalebar in $F^{\prime}$ is $5 \mu \mathrm{m}$. Scalebars in A-E' and in $\mathrm{F}-\mathrm{J}$ ' are the same. Asterisks in $\mathrm{K}$ and $\mathrm{L}$ represent a $\mathrm{P}<0.001$. lead to destabilization of the complex (Menon and Gaestel, 2015; Akhmetova et. al, 2018; Xu et. al, 2018). Therefore, we expressed Sep RNAi lines in FLP-OUT clones in the follicular epithelium together with UAS-nlsRedStinger, so any cells expressing Sep RNAi also expressed nuclear RFP. We then measured Pnut protein levels in the RFP-positive, follicle cells compared to RFP-negative cells. Clonal knockdown of Sep1 and Sep2, but not Sep4, led to a significant decrease in Pnut expression compared to neighboring control cells (Fig 3, A-E' and K). We observed similar results within the border cell cluster (Figure F-J' and L), supporting the idea that Sep1, Sep2, and Pnut interact to form stable complexes in border cells. We also observed similar results using c306Gal4 to drive UAS-RNAi together with UAS-LifeActin::GFP (Supplemental Figure 5).

To gain further insight into the Sep knockdown phenotypes in border cells, we performed live imaging. Control clusters dynamically change shape as they extend broad protrusions (Figure 4, A-F), deatch from the anterior and move toward the oocyte (Movie 1). By contrast, Sep1 RNAiexpressing border cell clusters were notably round and rarely extended protrusions at all (Figure 4G-L, Movie 2). The cells were mobile but did not move in between nurse cells toward the oocyte as the control cells do. $15-20 \%$ of Sep1 RNAi clusters never detached (Figure 4N, Movie 3). The Sep2 RNAi phenotype was even more severe with $63 \%$ of clusters failing to detach. When protrusions did form in Sep1 knockdown cells, they were abnormally thin (Figure 4O, Movie 4) compared to controls (Fig. 4M, Movie 1). These results suggest that septins are necessary for normal lead cell protrusive behavior and for trailing cell detachment but not for motility per se.
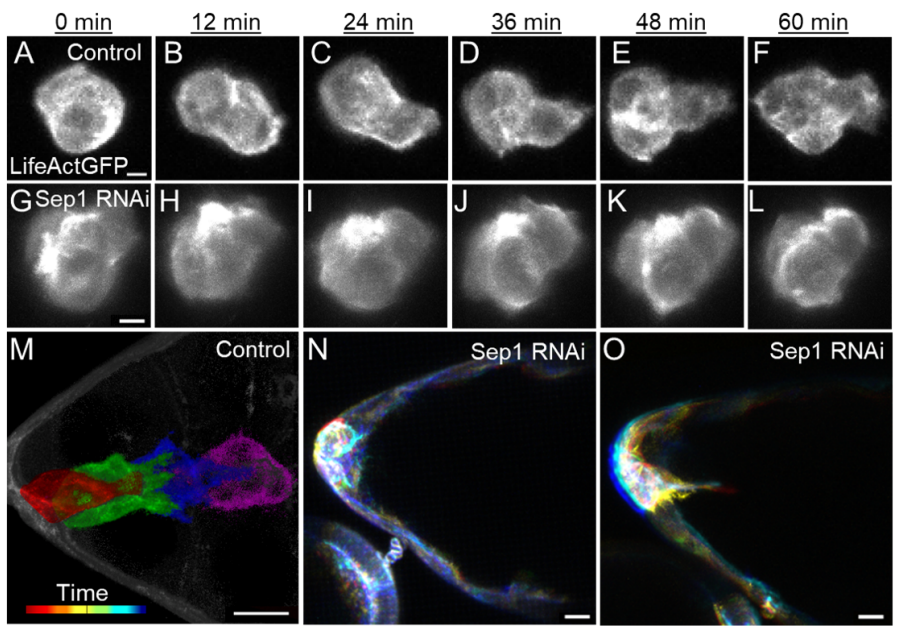

Figure 4. Live imaging reveals septins are required for detachment and directional migration. (A-F) Stills of border cell migration with 12 minutes between frames. The border cell cluster extends a wide frontward protrusion and retracts it. (G-L) Stills of border cell migration upon knockdown of Sep1. The cluster is rounded and does not extend protrusions. (M) Composite image of four time points showing detachment of a control border cell cluster. (N-O) Composite images of similar time points with Sep1 knockdown results in detachment failure. (O) The border cell cluster extends an abnormally long and thin protrusion but does not detach. The scalebar in A is $5 \mu \mathrm{m}$ and corresponds to A-F, the scalebar in $\mathrm{G}$ is $5 \mu \mathrm{m}$ and corresponds to $\mathrm{G}-\mathrm{L}$, and the scalebars in $\mathrm{M}, \mathrm{N}$, and $\mathrm{O}$ are $20 \mu \mathrm{m}$. 
bioRxiv preprint doi: https://doi.org/10.1101/2021.04.08.439079; this version posted April 10, 2021. The copyright holder for this preprint (which was not certified by peer review) is the author/funder, who has granted bioRxiv a license to display the preprint in perpetuity. It is made available under aCC-BY 4.0 International license.

Gabbert et al., 08 Apr 2021 - preprint copy - BioRxiv

Septins recognize micron-scale curvature (Bridges et. al 2016) and localize to the bud neck of $S$. cerevisiae undergoing cytokinesis. Yeast septins assemble differently on positively versus negatively curved membranes (Beber et. al 2019), and human septins are sufficient to induce tubulation of unilamellar lipid vesicles, where they assemble into concentric rings that provide mechanical support (Tanaka-Takiguchi et al., 2009). To examine septin localization in border cell clusters, we used high resolution z-stack images (Figure 5A) to model the 3D surface and localize septins relative to regions of convex or concave (from the intracellular perspective) curvature. Comparing the distributions of Pnut and F-actin revealed that F-actin was highly concentrated at the tip of the lead protrusion (Figure 5A and B, Movie 5), where Pnut was low (Figure $5 \mathrm{~A}$ and $\mathrm{C}$, Movie 5). On the other hand, Pnut accumulated near the base of protrusions (Figure 5B-E). At the base of the lead protrusions, rings of Pnut staining were evident (Figure 5B, C, E, Movie 5). We then used Tissue Cartography, a method for identifying curved surfaces (Heemskerk and Streichan 2015) to examine the relationship between septins and curved membranes (Figure 5C-F). We did not detect an obvious association with either convex or concave surfaces, which is perhaps not surprising, given that septins can associate with both (Beber et. al 2019). Together, the phenotype and localization implicate septins in providing mechanical support for border cell protrusions.
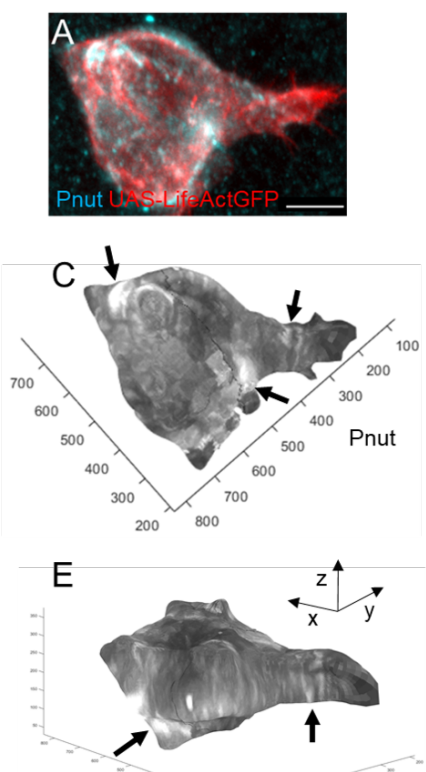
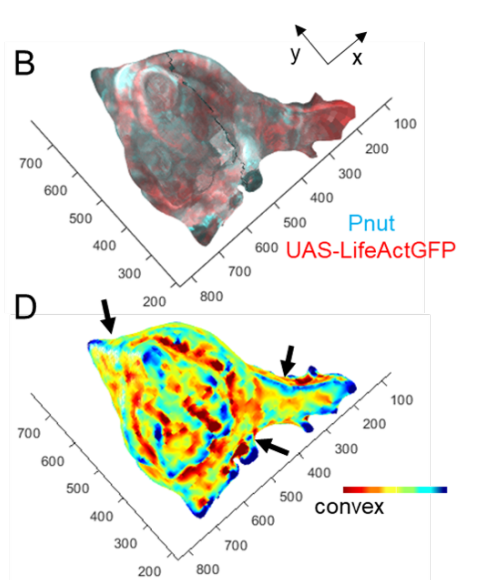

F

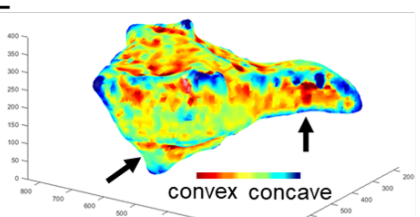

Figure 5. Pnut localizes to the base of protrusions and other convex regions. (A) High-resolution Airyscan max projection of a border cell cluster expressing LifeActGFP (red) and labeled with Pnut (cyan). (B) 3D model of the image from A, labeled with LifeActGFP (red) and Pnut (cyan). (C) 3D model from B showing only Pnut (gray), with arrows showing areas of high Pnut. (D) 3D curvature model of the same border cell cluster, with warm colors (reds) denoting convex curvature from the inside of the cluster and cool colors (blues) denoting concave curvature. (E) Rotated 3D model labeled with Pnut (gray), arrows show additional areas of high Pnut. (F) Rotated 3D curvature model. The scalebar in A is $5 \mu \mathrm{m}$.

To better understand the mechanistic function of septins during border cell migration, we tested for interactions with proteins known to interact with septins in other cell types. We first tested the impact of $\mathrm{Cdc} 42$, a Rho GTPase known to recruit septins to the yeast bud neck (Caviston et. al, 2003). We clonally expressed either one of two different Cdc42RNAi constructs or a constitutively active or a dominant negative version of Cdc42. We looked at Pnut localization in the epithelial follicle cells and in the border cell cluster. In each case, found no difference in expression level or localization in clones compared to neighboring control cells (Supplemental Figure 6). Thus, somewhat surprisingly, Cde42 activity does not appear to affect Pnut expression or localization.

Septins scaffold myosin in yeast and mammalian cells (Joo et. al, 2007; Schneider et. al, 2013), and myosin regulates border cell detachment and protrusion dynamics (Majumder et. al, 2012). Myosin also localizes to the base of protrusions to regulate protrusion retractions, and border cell clusters expressing a phosphomimetic form of myosin are rounded and bleb (Mishra et. al, 2019).
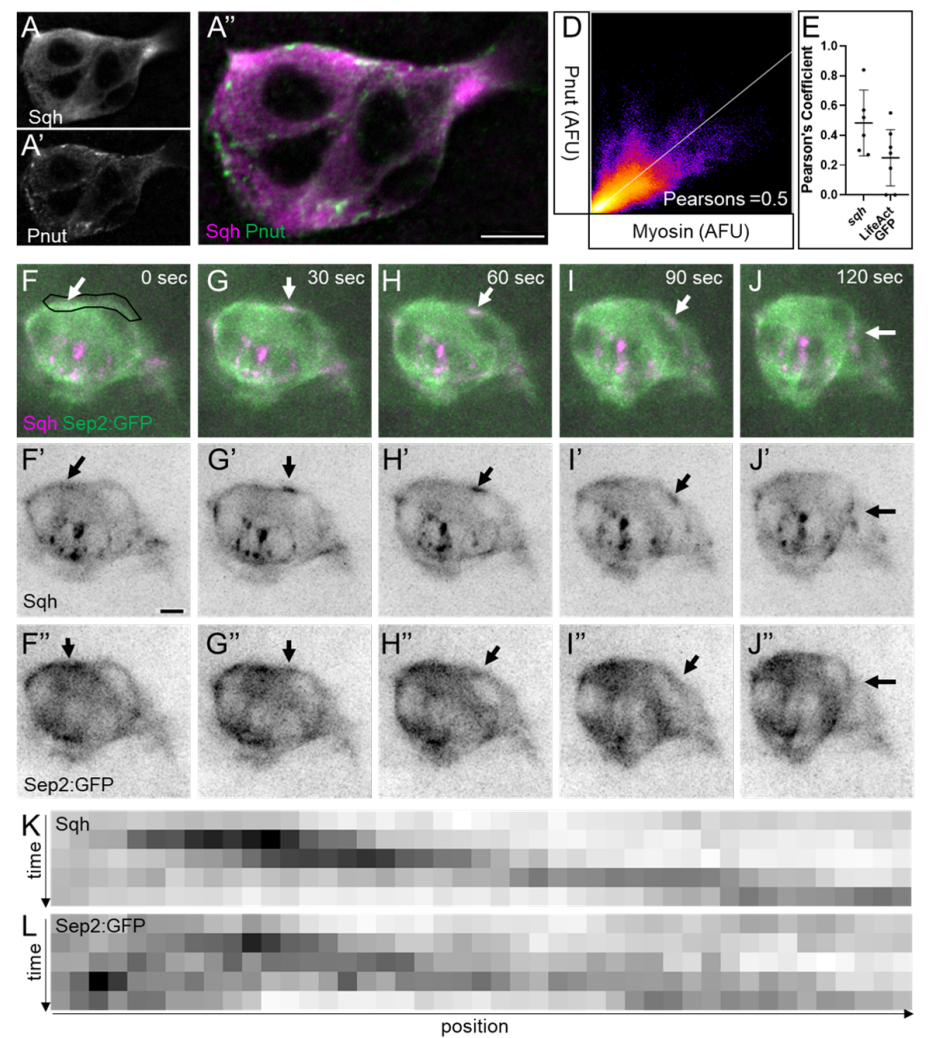

Figure 6. Pnut and Myosin dynamically co-localize at the protrusion neck and cluster periphery. (A-A") A single slice of a border cell cluster labeled with Sqh (A), Pnut (A'), or both (A"). (D-E) Sqh and Pnut colocalize in the border cell cluster with a Pearson's coefficient of 0.5 , compared to LifeActGFP as a control. (F-J) Max intensity stills of border cell migration with 30 second intervals between images labeled with Sqh (magenta) and Sep2:GFP (green). Arrows show myosin flashes colocalizing with Sep2. (F'-J') Images from F-J but labeled only with Sqh (black) to show myosin flashes over time. (F"-J") Images from F-J but labeled only with Sep2:GFP (black). (K-L) Kymographs of Sqh (K) or Sep2 (L) from 0 to 120 seconds in the periphery of the cluster, in the region shown by the arrows in F-J. Scalebar in A" is $5 \mu \mathrm{m}$. Scalebar in F' is $5 \mu \mathrm{m}$. The scalebar in F-J"' is the same.

To observe myosin expression and localization, we used flies expressing a tagged third copy of spaghetti squash (Sqh), which encodes the regulatory light chain of nonmuscle myosin II. High resolution Airyscan fixed imaging showed partial colocalization between Pnut and Sqh (Figure 6, A-D). As myosin is highly dynamic in the migrating border cell cluster, appearing as "myosin flashes" (Aranjuez et. al 2016, Mishra, 
bioRxiv preprint doi: https://doi.org/10.1101/2021.04.08.439079; this version posted April 10, 2021. The copyright holder for this preprint (which was not certified by peer review) is the author/funder, who has granted bioRxiv a license to display the preprint in perpetuity. It is made available under aCC-BY 4.0 International license.

Gabbert et al., 08 Apr 2021 - preprint copy - BioRxiv

et. al 2019), we conducted live imaging of clusters expressing both Sep2:GFP and Sqh:mCherry. We imaged at 30 second intervals to capture the rapid myosin flashes along the periphery. Transient colocalizations appear between myosin flashes and Sep2, which appears in broader domains (Figure 6, K-L).

\section{Discussion}

Cell shape is determined by interactions between the plasma membrane and the underlying cortical network of proteins. Migrating cells in particular undergo rapid changes in shape, and protrusions are especially important. It is striking that giant unilamellar vesicles (GUVs) spiked with phosphinositol 3,4-bis-phosphate form spheres in the absence of septins, but in the presence of human septins the GUVs form protrusions stabilized by concentric septin rings (Tanaka-Takiguchi et al., 2009). The hints of concentric septin rings at the base of the border cell forwarddirected protrusion together with the severe reduction in protrusions and nearly round shape of Sep RNAi-expressing border cell clusters suggests that a major function of septins in border cells may be to provide mechanical stability to protrusions.

Border cells face a particular challenge in that their protrusions have to pry apart the nurse cells in front of them. While much attention has focused on the ability of small GTPases like Rac and Cdc42 to stimulate actin polymerization, the force of actin polymerization may not be sufficient for protrusion in the face of obstacles. Similar to their functions at the base of cilia, dendrites, and yeast buds, septins may provide essential mechanical support for energetically unstable protuberances.

In addition, septins are known to scaffold other cytoskeletal elements. The most likely candidate in border cells is myosin II. Septin knockdowns share in common with myosin II knockdowns the failure of the cluster to detach from the anterior follicle cells and/or basement membrane surrounding the egg chamber. It is possible that septins recruit myosin, or vice versa. However not all septin phenotypes resemble myosin knockdowns. For example, knockdown of either the heavy or light chain of non-muscle myosin II in border cells results in ectopic protrusions and extra-long protrusions (Mishra et al., 2019), which is not a feature of septin knockdown cells. One model consistent with the observed phenotypes would be that septin stabilizes the base of the protrusion and recruits myosin, similar to its function at the bud neck. Only when myosin accumulates to a relatively high level does it contract with sufficient force to retract the protrusion or cleave the bud from the mother cell. We did not notice any phenotypic consequence of knocking down septins in other follicle cells, consistent with the proposal that septins are required for protrusion and retraction, behaviors specific to migratory border cells.

\section{Materials and Methods}

\section{Drosophila genetics}

Fly strains used in this study are listed in Supplementary Table 1. Detailed fly genotypes in each experiment are listed in Supplementary Table 2.

\section{Fly Husbandry}

Fly strains were raised in vials containing a standard cornmeal-yeast food (https://bdsc.indiana.edu/information/recipes/molassesfood.html) which contains $163 \mathrm{~g}$ yellow cornmeal, $33 \mathrm{~g}$ dried yeast, $200 \mathrm{~mL}$ molasses and $16 \mathrm{~g}$ agar with $2.66 \mathrm{~L}$ water. All flies were raised in vials containing $5 \mathrm{~mL}$ fly food.

\section{RNAi knockdown with Gal4 drivers}

2-4 day-old females were kept in $29 \mathrm{C}$ for 3 days, transferred to a vial with dry yeast each day until dissection. FLPout clones were first heat-shocked for one hour at $37 \mathrm{C}$ to induce clones, kept at room temperature for 8 hours, heat-shocked again at $37 \mathrm{C}$ for one hour, and then kept at $29 \mathrm{C}$ for 3 days with dry yeast until dissection.

\section{Egg chamber dissection and staining}

Adult female ovaries were dissected in Schneider's Drosophila medium (Thermo Fisher Scientific, Waltham, MA; 21720) with 20\% fetal bovine serum. Ovarioles containing egg chambers of the desired stages were pulled out of the muscle sheath with \#55 forceps.

For fixed sample staining, ovarioles were then fixed for $15 \mathrm{~min}$ in $4 \%$ paraformaldehyde. After fixation, ovarioles were washed with PBS/0.1\% Triton X-100 (PBST) or PBS/0.4\% Triton X-100 (PBST), and then incubated with primary antibodies overnight at $4{ }^{\circ} \mathrm{C}$. The following day, ovarioles were washed with PBST before incubation in secondary antibodies and Hoechst overnight at $4{ }^{\circ} \mathrm{C}$. The following day, ovarioles were again washed with PBST. Samples were stored in VECTASHIELD (Vector Laboratories, Burlingame, CA) at $4{ }^{\circ} \mathrm{C}$ before mounting.

The following antibodies and dyes were used in this study: Hoechst (1:1000, sigma-aldrich), rat anti-E-cadherin (1:25, DCAD2, DSHB), mouse anti-Pnut (1:50, 4C9H4, DSHB), rabbit anti-GFP (1:300, lifetech), rabbit anti-mCherry (1:500, novusbio), Alexa 488, 568, 647 (1:200, lifetech), phalloidin 647 (1:200, sigma-aldrich).

\section{Fixed Sample Imaging and Image Processing}

Samples were mounted on a glass slide in VECTASHIELD. Images were taken on a Zeiss LSM 800 confocal microscope, using a $20 \times 1.2$ N.A objective, 40x1.4 N.A. water objective, or $63 x, 0.8$ NA oil objective. images were taken on a Zeiss LSM 800 confocal microscope, using $63 \mathrm{x}, 0.8 \mathrm{NA}$ oil objective.

\section{Live Imaging}

Ovaries were dissected in Schneider's Drosophila medium (Thermo Fisher Scientific, Waltham, MA) with $20 \%$ fetal bovine serum. Individual ovarioles were carefully pulled out and stage 9 egg chambers were removed. The egg chambers were collected in a $0.6 \mathrm{~mL}$ tube and washed with dissecting medium twice, then added to $100 \mathrm{uL}$ dissecting medium with insulin (100 $\mathrm{ug} / \mathrm{uL}$ ) and $1 \%$ low melt agarose. $100 \mathrm{uL}$ medium with the egg chambers then were mounted on a $50 \mathrm{mmLumox}$ dish. Time-lapse imaging was performed using a $20 \times 1.2 \mathrm{~N}$.A. objective or $40 \times 1.1 \mathrm{NA}$ water immersion objective lens.

\section{Tissue Cartography and Curvature 3D Models}

We imaged migrating border cell clusters through high-resolution airyscan imaging. These images were imported into llastik (1), an opensource software for segmenting cells using machine learning. We used this to define the surface of the border cell cluster, and exported this file as a h5 file. This h5 file was imported into meshlab (2) to clean up the mesh as well as generate a file that can be analyzed using ImSAnE (Image Surface Analysis Environment) (6). Meshlab version used was MeshLab_64bit v1.3.3. Mesh construction was done by: 1 ) importing the cell surface; 2 ) Filters -> Sampling -> Poisson disc sampling. Base mesh subsampling option must be checked. Number of samples used was 15,000; 3) Filters $>$ Normals, Curvature and Orientation $->$ computing 5ormal for point sets 4) Filters $\rightarrow$ Remeshing, Simplification and Reconstruction $\rightarrow>$ surface reconstruction: poisson. The reconstructed surface is then exported as a PLY file with the flags and 5ormal data included.

The PLY file was analyzed using ImSAnE, details provided in the reference above as well as comments within the example scripts provided by the authors in their github [https://github.com/idse/imsane]. Specifically we modified the example script TutorialllastikDetectorSpherelikeFitter.m running on Matlab_R2019a.

\section{QUANTIFICATIONS AND STATISTICAL ANALYSES}

\section{Migration Defect Quantification}

For quantification of migration defects, stage 10 egg chambers were scored by eye. The position of the border cell clusters were assigned to categories of $0 \%, 1-25 \%, 26-50 \%, 51-75 \%$, or $76-100 \%$ based on their distance from the anterior of the egg chamber to the oocyte. 
bioRxiv preprint doi: https://doi.org/10.1101/2021.04.08.439079; this version posted April 10, 2021. The copyright holder for this preprint (which was not certified by peer review) is the author/funder, who has granted bioRxiv a license to display the preprint in perpetuity. It is made available under aCC-BY 4.0 International license.

Gabbert et al., 08 Apr 2021 - preprint copy - BioRxiv

\section{Colocalization Quantifications}

For quantification of Sep2 and Pnut or Pnut and Sqh colocalization, as well as LifeActGFP controls, high-resolution Airyscan z-stack images of the border cell cluster were taken at $63 x$ magnification with the $0.8 \mathrm{NA}$ oil objective. A single slice in the center of the z-stack was selected. A ROI was drawn to outline the cluster and background was subtracted. Colocalization of two channels within the ROI was measured using FIJI Coloc2 function (FIJI function: Analyze > Colocalization Analysis > Coloc 2). Pearson's correlation, $r$ was used as the readout of colozalization.

\section{Pnut intensity Quantifications}

For quantification of Pnut intensity, 20x, 40x, or $63 x$ images of Pnut channel were measured in FIJI. When measuring Pnut intensity in follicle cells or border cells, a single slice in the center of the $z$ stack was measured that clearly showed the cells of interest. All quantifications use integrated density.

\section{Sep2:GFP intensity Quantifications}

For quantification of Sep2:GFP intensity, samples were probed with antiGFP antibody. 20x images of GFP channel were measured in FIJI. When measuring Sep2:GFP intensity in follicle cells, a single slice in the center of the $z$ stack was measured that clearly showed the cells of interest. All quantifications use integrated density.

\section{Statistics and Data Presentation}

Standard statistical tests were performed using R Studio or Graphpad Prism. Ordinary one-way ANOVA, followed by Tukey's multiple comparisons test was used for comparing multiple groups with similar variance as determined by Brown-Forsythe test for Figure $3 \mathrm{~K}$ and $\mathrm{L}$ and Supplemental Figure $3 \mathrm{C}$ and $5 \mathrm{~B}$. All graphs were generated using Graphpad Prism. All confocal images belonging to the same experiment were acquired using the exact same settings. For visualization purposes, brightness adjustments were applied using FIJI to the confocal images shown in the figure panels. All quantitative analyses were carried out on unadjusted raw images. All fly crosses were repeated at least twice and ovary dissections and staining were repeated at least three times. Sample size was not predetermined by statistical methods but we used prior knowledge to estimate minimum sample size. The experiments were not randomized. Investigators were not blinded. The sample numbers $(\mathrm{N})$ for each figure are listed in figure legends.

\section{End Matter}

\section{Author Contributions and Notes}

Experiments were designed by A.M.G., J.A.M., J.P.C., and D.J.M. Experiments were carried out by A.M.G. J.P.C. and J.A.M. assisted with computer software and microscopy. Data analysis was performed by A.M.G. This manuscript was prepared by A.M.G., J.A.M., J.P.C., and D.J.M.

The authors declare no conflict of interest.

All data are available in the manuscript or the supplementary materials. Materials available upon request.

\section{Acknowledgments}

We thank the entire Montell lab for discussions and feedback. We thank Miles Keats, Nick Keefer, Eric Parella, and Spencer Phillips for technical assistance. Funding: This work was supported by NIH grant GM46425 to D.J.M and ACS grant PF-17-024-01-CSM to J.P.C. We thank the Developmental Studies Hybridoma Bank for providing antibodies and
Dr. Denise Clark, the Bloomington Drosophila Stock Center, and the Vienna Drosophila Resource Center for providing fly stocks.

\section{References}

1. Akhmetova, K., Dorogova, N. V., Chesnokov, I. N. \& Fedorova, S. A. Analysis of peanut Gene RNAi in Drosophila Oogenesis. Genetika 51 991-999 (2015).

2. Akhmetova, K. et al. Phosphorylation of Pnut in the Early Stages of Drosophila Embryo Development Affects Association of the Septin Complex with the Membrane and Is Important for Viability. G3 Genes|Genomes|Genetics 8, 27-38 (2018).

3. Aranjuez, G., Burtscher, A., Sawant, K., Majumder, P. \& McDonald, J. A. Dynamic myosin activation promotes collective morphology and migration by locally balancing oppositional forces from surrounding tissue. Mol Biol Cell 27, 1898-1910 (2016).

4. Beber, A. et al. Membrane reshaping by micrometric curvature sensitive septin filaments. Nature Communications 10, 420 (2019).

5. Berg, S., Kutra, D., Kroeger, T., Straehle, C.N., Kausler, B.X., Haubold, C., Schiegg, M., Ales, J., Beier, T., Rudy, M., Eren, K., Cervantes, J.I., Xu, B., Beuttenmueller, F., Wolny, A., Zhang, C., Koethe, U., Hamprecht, F.A., \& Kreshuk, A. ilastik: interactive machine learning for (bio)image analysis. Nature Methods, (2019).

6. Bridges, A. A., Jentzsch, M. S., Oakes, P. W., Occhipinti, P. \& Gladfelter, A. S. Micron-scale plasma membrane curvature is recognized by the septin cytoskeleton. Journal of Cell Biology 213, 23-32 (2016).

7. Caviston, J. P., Longtine, M., Pringle, J. R. \& Bi, E. The Role of Cdc42p GTPase-activating Proteins in Assembly of the Septin Ring in Yeast. MBoC 14, 4051-4066 (2003).

8. Cignoni, P., Callieri, M., Corsini, M., Dellepiane, M., Ganovelli, F., Ranzuglia, G. MeshLab: an Open-Source Mesh Processing Tool. Sixth Eurographics Italian Chapter Conference, 129-136, (2008).

9. Dolat, L. et al. Septins promote stress fiber-mediated maturation of focal adhesions and renal epithelial motility. Journal of Cell Biology 207, 225-235 (2014).

10. Edwards, K. A., Demsky, M., Montague, R. A., Weymouth, N. \& Kiehart, D. P. GFP-Moesin Illuminates Actin Cytoskeleton Dynamics in Living Tissue and Demonstrates Cell Shape Changes during Morphogenesis in Drosophila. Developmental Biology 191, 103-117 (1997).

11. Fares, H., Peifer, M. \& Pringle, J. R. Localization and possible functions of Drosophila septins. MBoC 6, 1843-1859 (1995).

12. Field, C. M. et al. A purified Drosophila septin complex forms filaments and exhibits GTPase activity. Journal of Cell Biology 133, 605-616 (1996).

13. Hartwell, L. H. Genetic control of the cell division cycle in yeast: IV. Genes controlling bud emergence and cytokinesis. Experimental Cell Research 69, 265-276 (1971).

14. Heemskerk, I. \& Streichan, S. J. Tissue Cartography: Compressing Bio-Image Data by Dimensional Reduction. Nat Methods 12, 11391142 (2015).

15. Joo, E., Surka, M. C. \& Trimble, W. S. Mammalian SEPT2 Is Required for Scaffolding Nonmuscle Myosin II and Its Kinases. Developmental Cell 13, 677-690 (2007).

16. Kinoshita, M. et al. Nedd5, a mammalian septin, is a novel cytoskeletal component interacting with actin-based structures. Genes Dev. 11, 1535-1547 (1997).

17. Kinoshita, M., Field, C. M., Coughlin, M. L., Straight, A. F. \& Mitchison, T. J. Self- and Actin-Templated Assembly of Mammalian Septins. Developmental Cell 3, 791-802 (2002).

18. Majumder, P., Aranjuez, G., Amick, J. \& McDonald, J. A. Par-1 Controls Myosin-Il Activity Through Myosin Phosphatase to Regulate Border Cell Migration. Curr Biol 22, 363-372 (2012). 
bioRxiv preprint doi: https://doi.org/10.1101/2021.04.08.439079; this version posted April 10, 2021. The copyright holder for this preprint (which was not certified by peer review) is the author/funder, who has granted bioRxiv a license to display the preprint in perpetuity. It is made available under aCC-BY 4.0 International license.

Gabbert et al., 08 Apr 2021 - preprint copy - BioRxiv

19. Miao, G., Godt, D. \& Montell, D. J. Integration of Migratory Cells into a New Site In Vivo Requires Channel-Independent Functions of Innexins on Microtubules. Developmental Cell 54, 501-515.e9 (2020).

20. Mishra, A. K., Mondo, J. A., Campanale, J. P. \& Montell, D. J. Coordination of protrusion dynamics within and between collectively migrating border cells by myosin II. MBoC 30, 2490-2502 (2019).

21. Montell, D. J., Rorth, P. \& Spradling, A. C. slow border cells, a locus required for a developmentally regulated cell migration during oogenesis, encodes Drosophila CEBP. Cell 71, 51-62 (1992).

Montell, D. J. Border-cell migration: the race is on. Nature Reviews Molecular Cell Biology 4, 13-24 (2003).

22. Montell, D. J., Yoon, W. H. \& Starz-Gaiano, M. Group choreography: mechanisms orchestrating the collective movement of border cells. Nat Rev Mol Cell Biol 13, 631-645 (2012).

23. Mostowy, S. \& Cossart, P. Septins: the fourth component of the cytoskeleton. Nature Reviews Molecular Cell Biology 13, 183-194 (2012).

24. Murphy, A. M. \& Montell, D. J. Cell type-specific roles for Cdc42, Rac, and RhoL in Drosophila oogenesis. Journal of Cell Biology 133, 617630 (1996).

25. O'Neill, R. S. \& Clark, D. V. Partial Functional Diversification of Drosophila melanogaster Septin Genes Sep2 and Sep5. G3 Genes|Genomes|Genetics 6, 1947-1957 (2016).

26. Oh, Y. \& Bi, E. Septin structure and function in yeast and beyond. Trends in Cell Biology 21, 141-148 (2011).

27. Peterson, E. A. \& Petty, E. M. Conquering the complex world of human septins: implications for health and disease. Clinical Genetics 77, 511-524 (2010).

28. Schneider, C., Grois, J., Renz, C., Gronemeyer, T. \& Johnsson, N. Septin rings act as a template for myosin higher-order structures and inhibit redundant polarity establishment. J Cell Sci 126, 3390-3400 (2013).
29. Seetharaman, S. \& Etienne-Manneville, S. Cytoskeletal Crosstalk in Cell Migration. Trends in Cell Biology 30, 720-735 (2020).

30. Shinoda, T. et al. Septin 14 Is Involved in Cortical Neuronal Migration via Interaction with Septin 4. Molecular Biology of the Cell 21, 11 (2010).

31. Silver, D. L. \& Montell, D. J. Paracrine Signaling through the JAK/STAT Pathway Activates Invasive Behavior of Ovarian Epithelial Cells in Drosophila. Cell 107, 831-841 (2001).

32. Silver, D. L., Geisbrecht, E. R. \& Montell, D. J. Requirement for JAK/STAT signaling throughout border cell migration in Drosophila. Development 132, 3483-3492 (2005).

33. Tanaka-Takiguchi, Y., Kinoshita, M. \& Takiguchi, K. Septin-Mediated Uniform Bracing of Phospholipid Membranes. Current Biology 19, 140-145 (2009).

34. Tooley, A. J. et al. Amoeboid T lymphocytes require the septin cytoskeleton for cortical integrity and persistent motility. Nature Cell Biology 11, 17-26 (2009).

35. Wang, X. et al. Analysis of cell migration using whole-genome expression profiling of migratory cells in the Drosophila ovary. Dev Cell 10, 483-495 (2006).

36. Woods, B. L. \& Gladfelter, A. S. The state of the septin cytoskeleton from assembly to function. Current Opinion in Cell Biology 68, 105112 (2021).

Xi, R., McGregor, J. R. \& Harrison, D. A. A Gradient of JAK Pathway Activity Patterns the Anterior-Posterior Axis of the Follicular Epithelium. Developmental Cell 4, 167-177 (2003).

37. Xu, D. et al. Repression of Septin9 and Septin2 suppresses tumor growth of human glioblastoma cells. Cell Death \& Disease $9,1-13$ (2018).

38. Xue, Z. \& Sokac, A. M. -Back-to-back mechanisms drive actomyosin ring closure during Drosophila embryo cleavage. Journal of Cell Biology 215, 335-344 (2016). 
bioRxiv preprint doi: https://doi.org/10.1101/2021.04.08.439079; this version posted April 10, 2021. The copyright holder for this preprint (which

was not certified by peer review) is the author/funder, who has granted bioRxiv a license to display the preprint in perpetuity. It is made available under aCC-BY 4.0 International license.

A

Human Drosophila

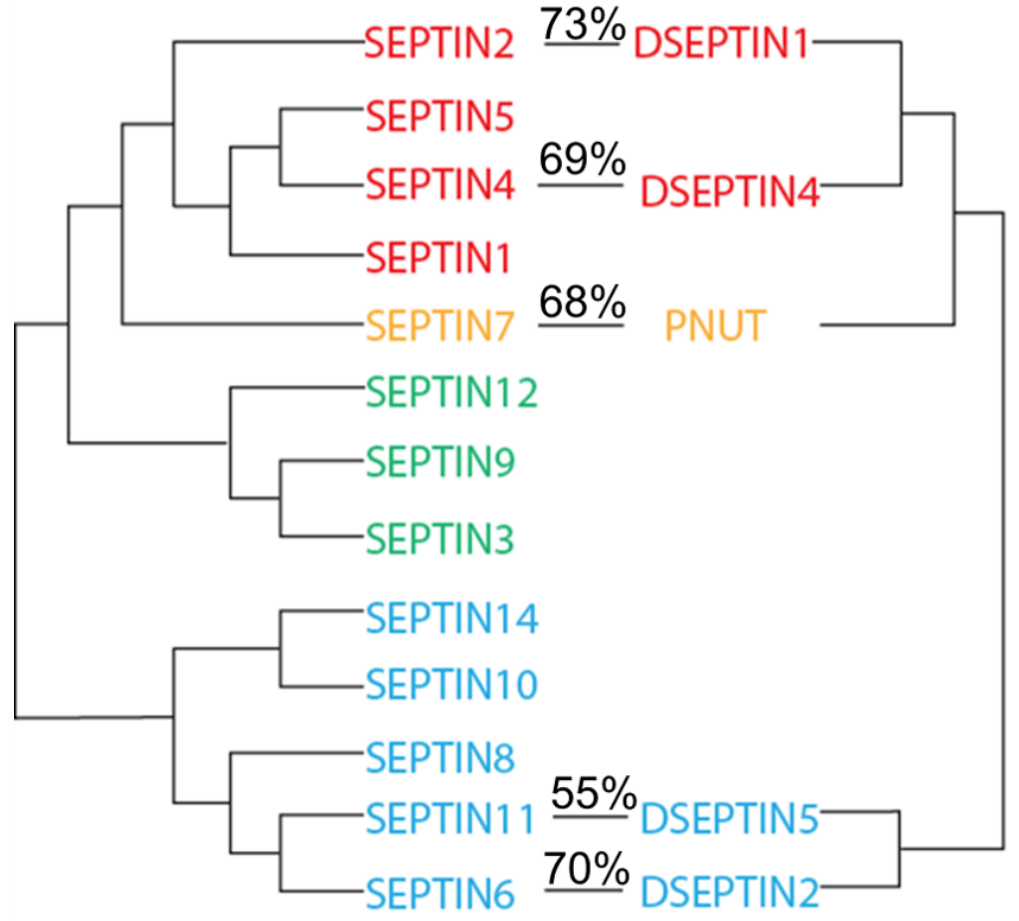

Supplemental Figure 1. Drosophila septins have high similarity to their human orthologs. Humans have 13 septins while Drosophila have 5. 
bioRxiv preprint doi: https://doi.org/10.1101/2021.04.08.439079; this version posted April 10, 2021. The copyright holder for this preprint (which was not certified by peer review) is the author/funder, who has granted bioRxiv a license to display the preprint in perpetuity. It is made available under aCC-BY 4.0 International license.

Gabbert et al., 08 Apr 2021 - preprint copy - BioRxiv
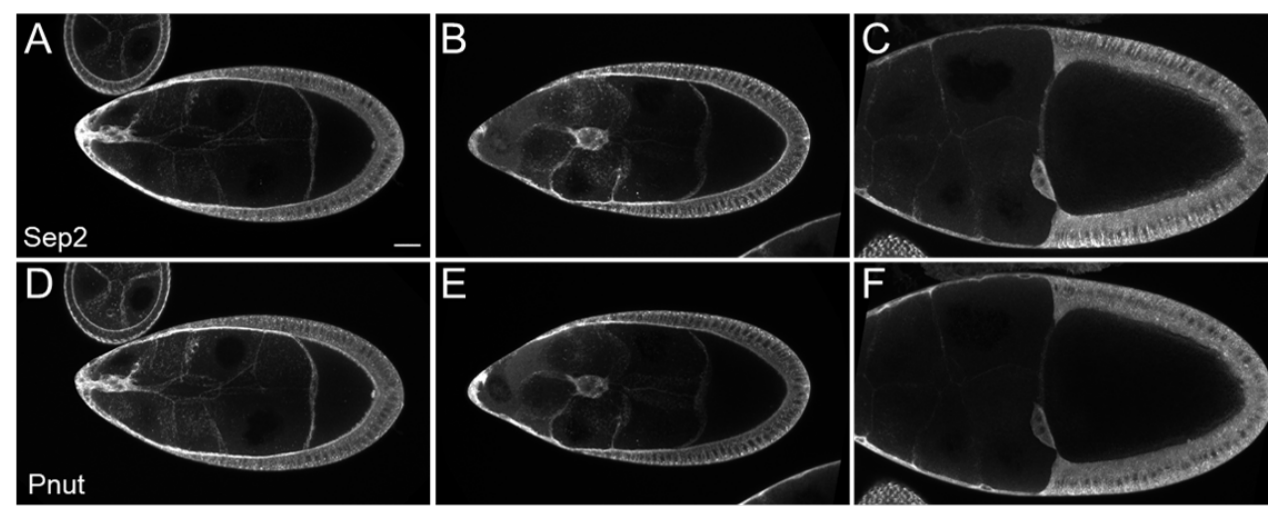

Supplemental Figure 2. Pnut and Sep2 are expressed throughout border cell migration. Max intensity projections of egg chambers labeled with Pnut (gray) (A-C) or Sep2 (gray) (D-F). The scalebar in A is $20 \mu \mathrm{m}$. The scalebar in A-F is the same. 
bioRxiv preprint doi: https://doi.org/10.1101/2021.04.08.439079; this version posted April 10, 2021. The copyright holder for this preprint (which was not certified by peer review) is the author/funder, who has granted bioRxiv a license to display the preprint in perpetuity. It is made available under aCC-BY 4.0 International license.

Gabbert et al., 08 Apr 2021 - preprint copy - BioRxiv
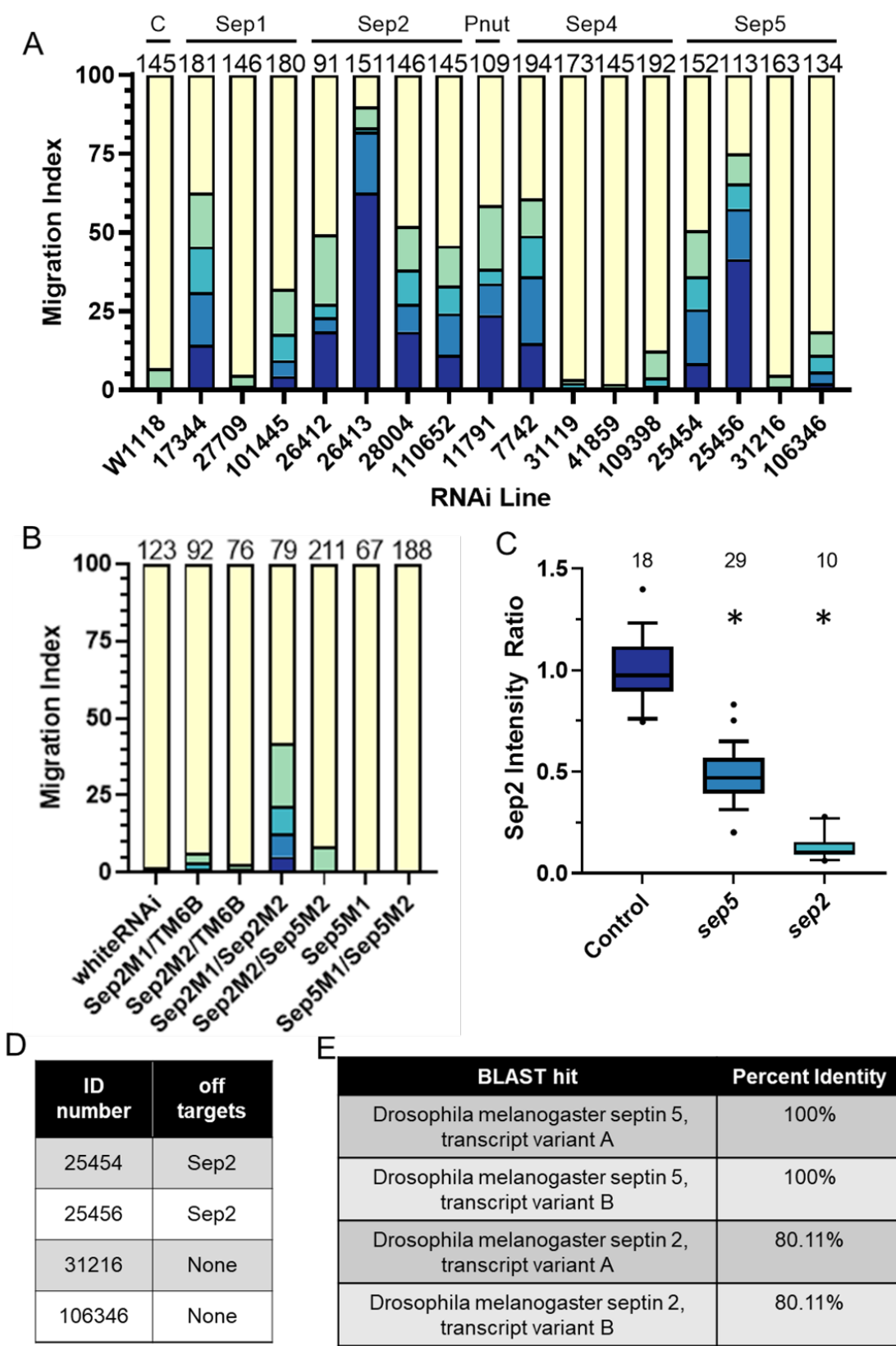

Supplemental Figure 3. Impaired migration in Sep5 knockdowns due to off target of Sep2 transcripts. (A) Screen of septin RNAi lines and their impact on border cell migration. (B) Impact of septin mutants on migration. (C) Sep2 intensity in posterior follicle cells expressing septin RNAi compared to mid follicle cells that do not express the knockdown. (D) VDRC ID numbers of septin RNAi lines and if they have off targets. (E) BLAST of Sep5 RNAi line 25454, with hits from Sep5 and from Sep2. Asterisks in C represent a $P$ value less than 0.001 . 
bioRxiv preprint doi: https://doi.org/10.1101/2021.04.08.439079; this version posted April 10, 2021. The copyright holder for this preprint (which was not certified by peer review) is the author/funder, who has granted bioRxiv a license to display the preprint in perpetuity. It is made available under aCC-BY 4.0 International license.

Gabbert et al., 08 Apr 2021 - preprint copy - BioRxiv

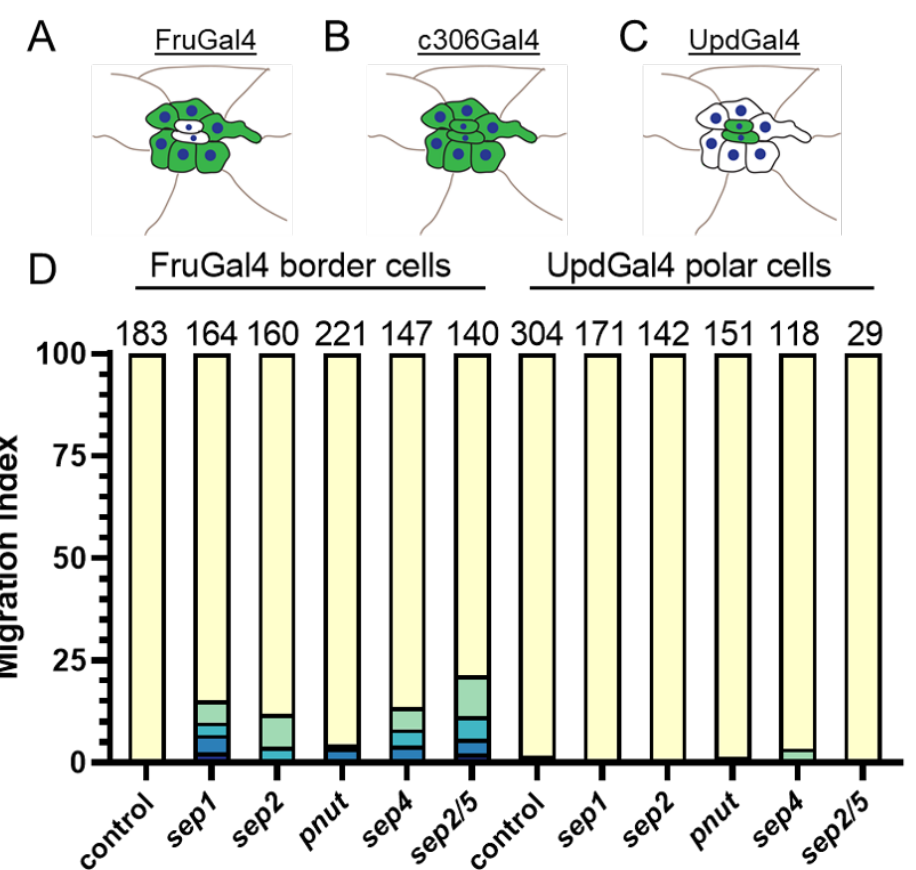

RNAi
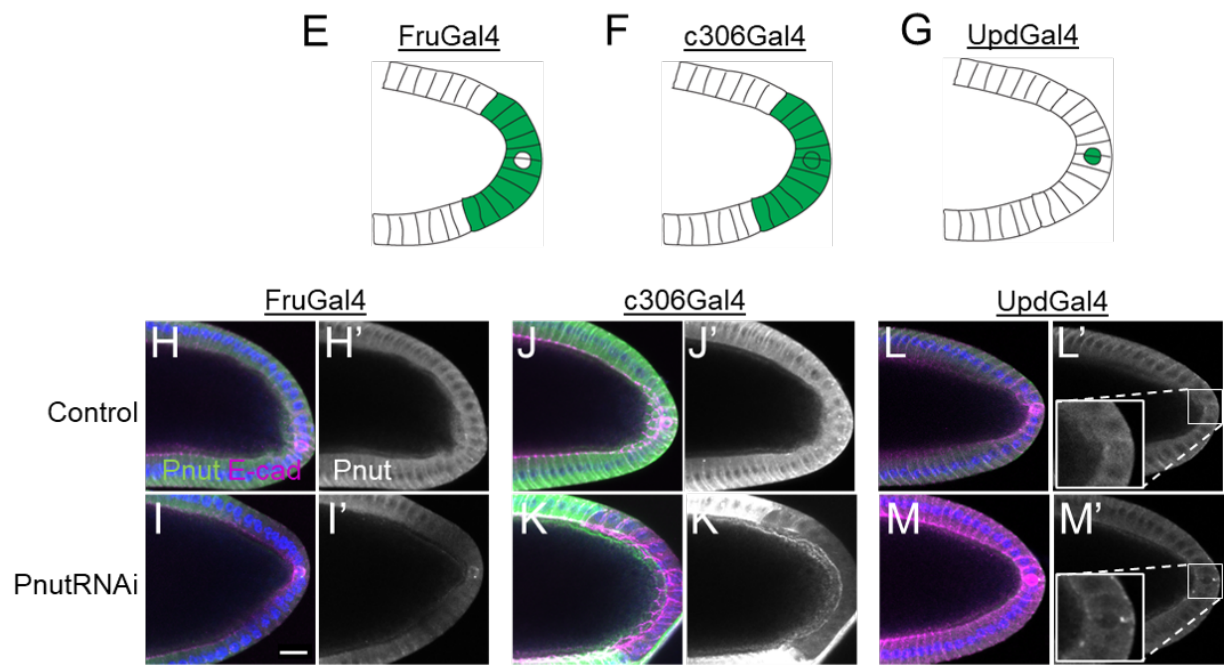

Supplemental Figure 4. Migratory border cells require septins and non-motile polar cells do not. (A-C) Expression patterns for FruGal4, c306Gal4, and UpdGal4 in the border cell cluster. (D) Septin knockdown using FruGal4 or UpdGal4. (E-G) Expression patterns for FruGal4, c306Gal4, and UpdGal4 in the posterior of the egg chamber. (H-H') Posterior follicle cells expressing whiteRNAi with FruGal4 labeled with Pnut (green) and E-cadherin (magenta) $(\mathrm{H}$ ) or only Pnut (gray) $\left(\mathrm{H}^{\prime}\right)$. (I-I') Posterior follicle cells expressing PnutRNAi with FruGal4 labeled with Pnut (green) and E-cadherin (magenta) (I) or only Pnut (gray) (I'). (J-J') Posterior follicle cells expressing whiteRNAi with c306Gal4 labeled with Pnut (green) and E-cadherin (magenta) (J) or only Pnut (gray) (J'). (KK') Posterior follicle cells expressing PnutRNAi with c306Gal4 labeled with Pnut (green) and Ecadherin (magenta) (K) or only Pnut (gray) (K'). (L-L') Posterior follicle cells expressing whiteRNAi with UpdGal4 labeled with Pnut (green) and E-cadherin (magenta) (L) or only Pnut (gray) (L'). (MM') Posterior follicle cells expressing PnutRNAi with UpdGal4 labeled with Pnut (green) and Ecadherin (magenta) (M) or only Pnut (gray) (M'). The scalebar in I is $20 \mu \mathrm{m}$. The scalebars in H-M' are the same. 
bioRxiv preprint doi: https://doi.org/10.1101/2021.04.08.439079; this version posted April 10, 2021. The copyright holder for this preprint (which was not certified by peer review) is the author/funder, who has granted bioRxiv a license to display the preprint in perpetuity. It is made available under aCC-BY 4.0 International license.
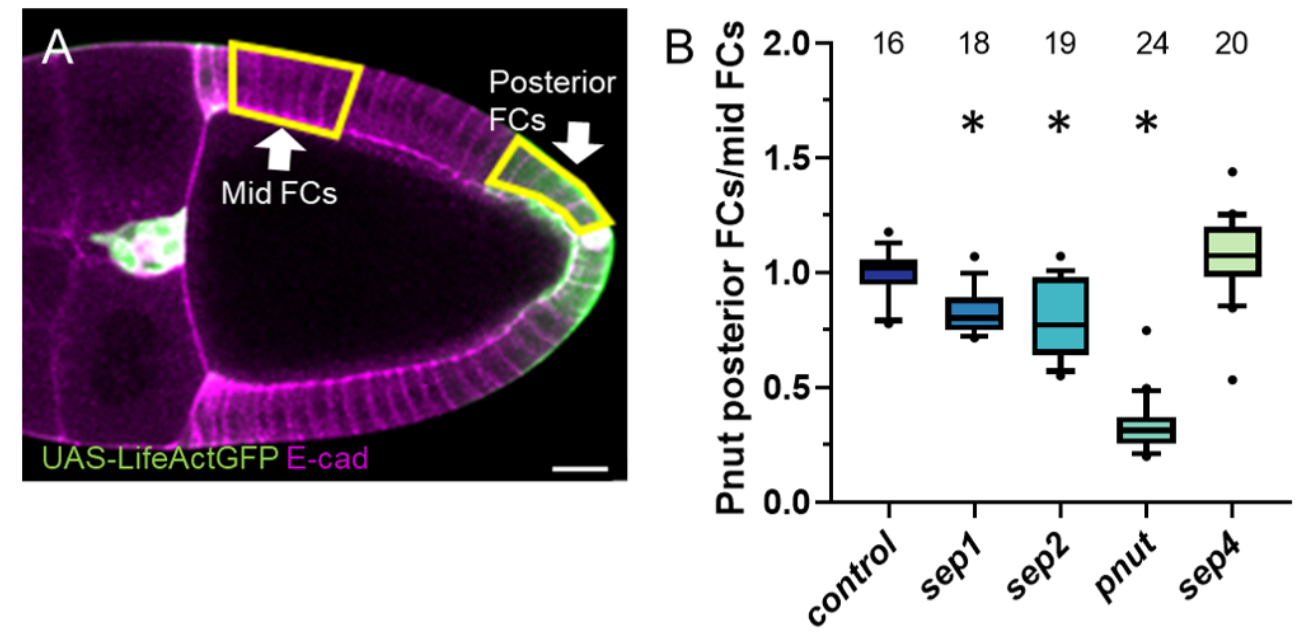

Supplemental Figure 5. Pnut expression in the posterior non-migrating epithelial follicle cells is dependent on Sep1 and 2. (A) Follicle cell quantification method. Posterior follicle cells express LifeActGFP and septin RNAi and mid follicle cells do not express either. (B) Pnut intensity in GFP positive posterior polar cells compared to Pnut intensity in GFP negative mid follicle cells. Asterisks in $B$ represent a $P$ value less than 0.01 . 
bioRxiv preprint doi: https://doi.org/10.1101/2021.04.08.439079; this version posted April 10, 2021. The copyright holder for this preprint (which was not certified by peer review) is the author/funder, who has granted bioRxiv a license to display the preprint in perpetuity. It is made available under aCC-BY 4.0 International license.

Gabbert et al., 08 Apr 2021 - preprint copy - BioRxiv

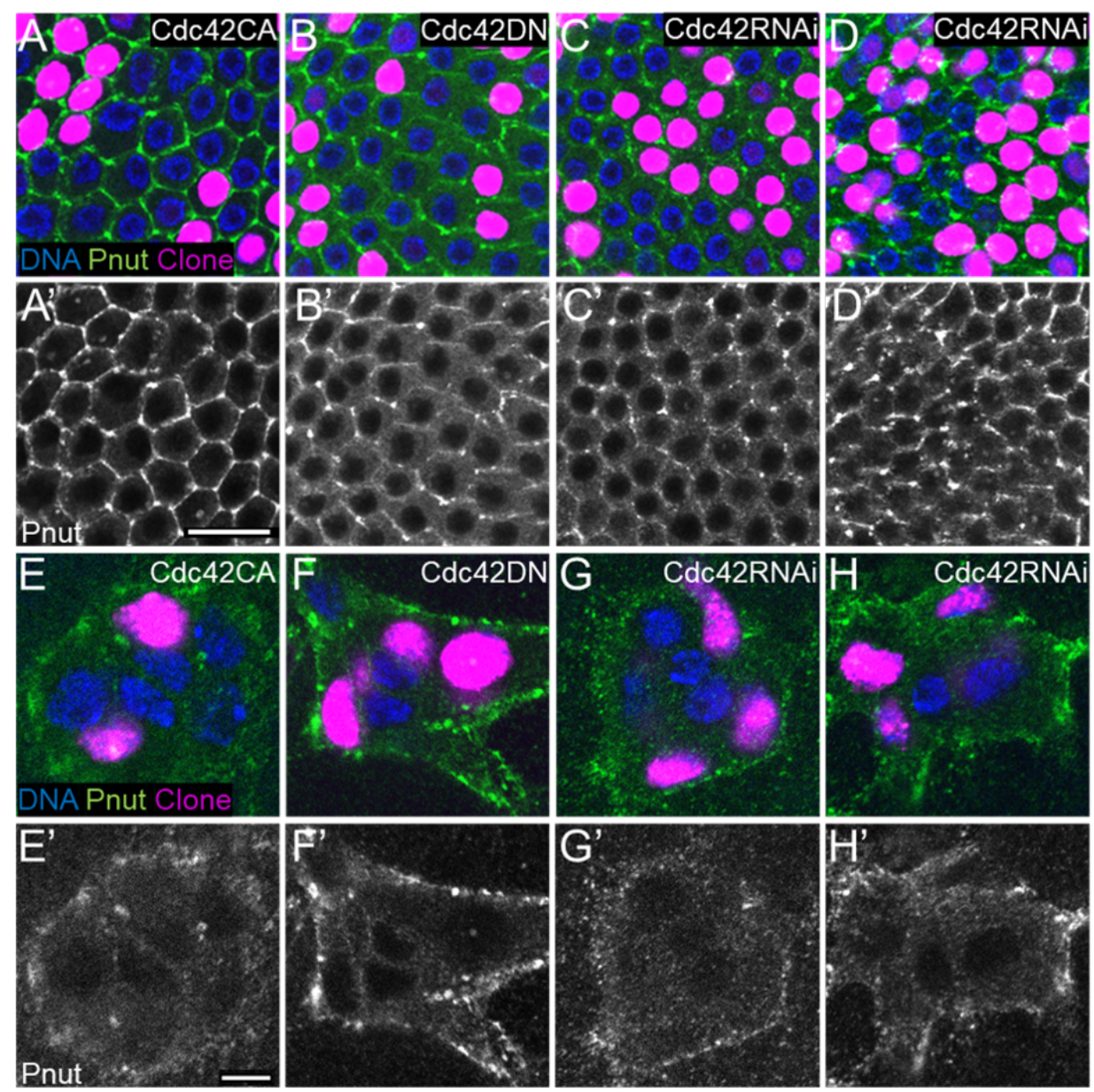

Supplemental Figure 6. Cdc42 activity does not impact Pnut expression or localization. (A$\left.A^{\prime}\right)$ Single slice images of epithelial follicle cells on the basal surface of the egg chamber expressing Cdc42CA labeled with Hoechst (blue) and Pnut (green) (A) or only Pnut (gray) (A'). (B-B') Single slice images of epithelial follicle cells on the basal surface of the egg chamber expressing Cdc42DN labeled with Hoechst (blue) and Pnut (green) (B) or only Pnut (gray) (B'). (C-C' and D-D') Single slice images of epithelial follicle cells on the basal surface of the egg chamber expressing two different Cdc42 RNAi lines labeled with Hoechst (blue) and Pnut (green) (C and D) or only Pnut (gray) (C' and D'). (E-E') Single slice images of border cell clusters expressing Cdc42CA labeled with Hoechst (blue) and Pnut (green) (E) or only Pnut (gray) (E'). (F-F') Single slice images of border cell clusters expressing Cdc42DN labeled with Hoechst (blue) and Pnut (green) (F) or only Pnut (gray) (F'). (G-G' and H-H') Single slice images of border cell clusters expressing two different Cdc42 RNAi lines labeled with Hoechst (blue) and Pnut (green) ( $G$ and $H$ ) or only Pnut (gray) ( $G^{\prime}$ and $\left.H^{\prime}\right)$. (A-D and $\left.E-H\right)$ Clones are marked with magenta nuclei, expressing nuclear-localized RedStinger. The scalebar in $A^{\prime}$ is $20 \mu \mathrm{m}$ and the scalebar in $E^{\prime}$ is $5 \mu \mathrm{m}$. Scalebars in A-D' and in E$H^{\prime}$ are the same. 
bioRxiv preprint doi: https://doi.org/10.1101/2021.04.08.439079; this version posted April 10, 2021. The copyright holder for this preprint (which was not certified by peer review) is the author/funder, who has granted bioRxiv a license to display the preprint in perpetuity. It is made available under aCC-BY 4.0 International license.

Gabbert et al., 08 Apr 2021 - preprint copy - BioRxiv

Supplemental Table 1: List of fly strains used in this study

\begin{tabular}{|c|c|}
\hline Genotype & Source \\
\hline c306Gal4;UAS-LifeActGFP;Gal80ts & lab stock \\
\hline sep2:GFP & BDSC 26257 \\
\hline UAS-whiteRNAi/cyo & lab stock \\
\hline UAS-sep1RNAi & BDSC 27709 \\
\hline UAS-sep1RNAi & VDRC 17344 \\
\hline UAS-sep1RNAi & VDRC 101445 \\
\hline UAS-sep2RNAi & BDSC 28004 \\
\hline UAS-sep2RNAi & VDRC 26412 \\
\hline UAS-sep2RNAi & VDRC 26413 \\
\hline UAS-sep2RNAi & VDRC 110652 \\
\hline UAS-pnutRNAi & VDRC 11791 \\
\hline UAS-sep4RNAi & BDSC 31119 \\
\hline UAS-sep4RNAi & BDSC 41859 \\
\hline UAS-sep4RNAi & VDRC 7742 \\
\hline UAS-sep4RNAi & VDRC 109398 \\
\hline UAS-sep5RNAi & BDSC 31216 \\
\hline UAS-sep5RNAi & VDRC 25454 \\
\hline UAS-sep5RNAi & VDRC 25456 \\
\hline UAS-sep5RNAi & VDRC 106346 \\
\hline hsFLP;AyGal4-25b,UASredstingerNLS & lab stock \\
\hline sqh:sqh-mcherry & BDSC 59024 \\
\hline $\mathrm{Cdc} 42 \mathrm{CA}$ & BDSC 4854 \\
\hline Cdc42DN & BDSC 6288 \\
\hline Cdc42 RNAi & VDRC 330192 \\
\hline Cdc42 RNAi & VDRC 100794 \\
\hline Gal80ts;FruGal4 & lab stock \\
\hline Updgal4;;Gal80ts & lab stock \\
\hline
\end{tabular}


bioRxiv preprint doi: https://doi.org/10.1101/2021.04.08.439079; this version posted April 10, 2021. The copyright holder for this preprint (which was not certified by peer review) is the author/funder, who has granted bioRxiv a license to display the preprint in perpetuity. It is made available under aCC-BY 4.0 International license.

Gabbert et al., 08 Apr 2021 - preprint copy - BioRxiv

Supplemental Table 2: List of fly genotypes in each experiment

\begin{tabular}{|c|c|c|c|}
\hline Figure & Panel & Group & Genotype \\
\hline 1 & D-F" & control & c306Gal4;UAS-LifeActGFP;UAS-whiteRNAi/Gal80ts \\
\hline 1 & G-J" & control & sep2:GFP \\
\hline 2 & A & control & c306Gal4;UAS-LifeActGFP;UAS-whiteRNAi/Gal80ts \\
\hline 2 & $\mathrm{~B}$ & Sep1 RNAi & c306Gal4;UAS-LifeActGFP;UAS-sep1RNAi/Gal80ts \\
\hline 2 & $\mathrm{C}$ & Sep2 RNAi & c306Gal4;UAS-LifeActGFP;UAS-sep2RNAi/Gal80ts \\
\hline 2 & $\mathrm{D}$ & Pnut RNAi & c306Gal4/pnutRNAi;UAS-LifeActGFP;Gal80ts \\
\hline 2 & $\mathrm{E}$ & Sep4 RNAi & c306Gal4;UAS-LifeActGFP;UAS-sep4RNAi/Gal80ts \\
\hline 2 & $\mathrm{~F}$ & Sep5 RNAi & c306Gal4;UAS-LifeActGFP;UAS-sep5RNAi/Gal80ts \\
\hline 3 & $\mathrm{~A}, \mathrm{~A}^{\prime}, \mathrm{F}, \mathrm{F}^{\prime}$ & control & hsFLP;AyGal4-25b,UASredstingerNLS; whiteRNAi \\
\hline 3 & $\mathrm{~B}, \mathrm{~B}^{\prime}, \mathrm{G}, \mathrm{G}^{\prime}$ & Sep1 FLPout RNAi & hsFLP;AyGal4-25b,UASredstingerNLS;sep1RNAi \\
\hline 3 & $\mathrm{C}, \mathrm{C}^{\prime}, \mathrm{H}, \mathrm{H}^{\prime}$ & Sep2 FLPout RNAi & hsFLP;AyGal4-25b,UASredstingerNLS;sep2RNAi \\
\hline 3 & $\mathrm{D}, \mathrm{D}^{\prime}, \mathrm{I}, \mathrm{I}^{\prime}$ & Pnut FLPout RNAi & hsFLP/pnutRNAi;AyGal4-25b,UASredstingerNLS \\
\hline 3 & $\mathrm{E}, \mathrm{E}^{\prime}, \mathrm{J}, \mathrm{J}^{\prime}$ & Sep4 FLPout RNAi & hsFLP;AyGal4-25b,UASredstingerNLS;sep4RNAi \\
\hline 4 & A-F & control & c306Gal4;UAS-LifeActGFP;UAS-whiteRNAi/Gal80ts \\
\hline 4 & G-L & Sep1 RNAi & c306Gal4;UAS-LifeActGFP;UAS-sep1RNAi/Gal80ts \\
\hline 4 & $\mathrm{M}$ & control & sep2:GFP \\
\hline 4 & $\mathrm{~N}$ & Sep1 RNAi & c306Gal4;UAS-LifeActGFP;UAS-sep1RNAi/Gal80ts \\
\hline 4 & $\mathrm{O}$ & Sep1 RNAi & c306Gal4;UAS-LifeActGFP;UAS-sep1RNAi/Gal80ts \\
\hline 5 & A-F & control & c306Gal4;UAS-LifeActGFP;Gal80ts \\
\hline 6 & A-A" & sqh:mcherry & sqh:sqh-mcherry;MKRS/TM6B \\
\hline 6 & F-J" & control & sqh:sqh-mcherry;sep2:GFP \\
\hline $\mathrm{S} 2$ & A-C & control & c306Gal4;UAS-LifeActGFP;UAS-whiteRNAi/Gal80ts \\
\hline $\mathrm{S} 2$ & $\mathrm{D}-\mathrm{F}$ & control & sep2:GFP \\
\hline S3 & A & control & c306Gal4;UAS-LifeActGFP;UAS-whiteRNAi/Gal80ts \\
\hline \multirow[t]{3}{*}{ S3 } & A & Sep1-5 RNAi & c306Gal4/sepRNAi;UAS-LifeActGFP;Gal80ts \\
\hline & & & c306Gal4;UAS-sepRNAi/UAS-LifeActGFP;Gal80ts \\
\hline & & & c306Gal4;UAS-LifeActGFP;UAS-sepRNAi/Gal80ts \\
\hline $\mathrm{S} 3$ & $\mathrm{~B}$ & control & c306Gal4;UAS-LifeActGFP;UAS-whiteRNAi/Gal80ts \\
\hline $\mathrm{S} 3$ & $\mathrm{~B}$ & Sep2 heterozygous mutant & Sep2M ${ }^{1} / \mathrm{TM} 6 \mathrm{~B}$ \\
\hline $\mathrm{S} 3$ & $\mathrm{~B}$ & Sep2 heterozygous mutant & Sep2M $2 / T M 6 B$ \\
\hline $\mathrm{S} 3$ & $\mathrm{~B}$ & Sep2 trans-heterozygous mutant & Sep $2 M^{1} / \operatorname{Sep} 2 M^{2}$ \\
\hline $\mathrm{S} 3$ & $\mathrm{~B}$ & Sep2 and Sep5 heterozygous mutant & Sep $2 \mathrm{M}^{2} / \mathrm{Sep} 5 \mathrm{M}^{2}$ \\
\hline $\mathrm{S3}$ & $\mathrm{B}$ & Sep5 homozygous mutant & Sep5 $\mathrm{M}^{1}$ \\
\hline S3 & $\mathrm{B}$ & Sep5 trans-heterozygous mutant & Sep5 $\mathrm{M}^{1} / \mathrm{Sep} 5 \mathrm{M}^{2}$ \\
\hline $\mathrm{S3}$ & $\mathrm{C}$ & control & c306Gal4;sep2:GFP/UAS-whiteRNAi \\
\hline $\mathrm{S} 3$ & $\mathrm{C}$ & Sep2 RNAi & c306Gal4;sep2:GFP/UAS-sep2RNAi \\
\hline S3 & C & Sep5 RNAi & c306Gal4;sep2:GFP/UAS-sep5RNAi \\
\hline S4 & $\mathrm{D}, \mathrm{H}, \mathrm{I}$ & control & Gal80ts;FruGal4/UAS-whiteRNAi \\
\hline S4 & $\mathrm{D}$ & Sep1-5 RNAi & sepRNAi;Gal80ts;FruGal4 \\
\hline S4 & $\mathrm{D}, \mathrm{H}^{\prime}-\mathrm{I}^{\prime}$ & Pnut RNAi & pnutRNAi;Gal80ts;FruGal4 \\
\hline S4 & $\mathrm{J}-\mathrm{K}$ & control & c306Gal4;UAS-LifeActGFP;UAS-whiteRNAi/Gal80ts \\
\hline S4 & $J^{\prime}-K^{\prime}$ & Pnut RNAi & c306Gal4/pnutRNAi;UAS-LifeActGFP;Gal80ts \\
\hline S4 & D, L-M & control & Updgal4;;UAS-whiteRNAi/Gal80ts \\
\hline S4 & $\mathrm{D}$ & Sep1-5 RNAi & Updgal4;;UAS-sepRNAi/Gal80ts \\
\hline S4 & $\mathrm{D}, \mathrm{L}^{\prime}-\mathrm{M}^{\prime}$ & Pnut RNAi & Updgal4/UAS-sepRNAi;;Gal80ts \\
\hline S5 & A-B & control & c306Gal4;UAS-LifeActGFP;UAS-whiteRNAi/Gal80ts \\
\hline S5 & A-B & Sep1, 2, or 4 RNAi & c306Gal4;UAS-LifeActGFP;UAS-sepRNAi/Gal80ts \\
\hline S5 & $\mathrm{B}$ & Pnut RNAi & c306Gal4/UAS-pnutRNAi;UAS-LifeActGFP;Gal80ts \\
\hline S6 & A-B & control & c306Gal4;UAS-LifeActGFP;Gal80ts \\
\hline S7 & $\mathrm{A}, \mathrm{A}^{\prime}, \mathrm{E}, \mathrm{E}^{\prime}$ & Cdc42CA FLPout & hsFLP;AyGal4-25b,UASredstingerNLS/UAS-Cdc42CA \\
\hline S7 & $\mathrm{B}, \mathrm{B}^{\prime}, \mathrm{F}, \mathrm{F}^{\prime}$ & Cdc42DN FLPout & hsFLP;AyGal4-25b,UASredstingerNLS/UAS-Cdc42DN \\
\hline $\mathrm{S} 7$ & $\mathrm{C}, \mathrm{C}^{\prime}, \mathrm{G}, \mathrm{G}^{\prime}$ & Cdc42 FLPout RNAi & hsFLP;AyGal4-25b,UASredstingerNLS/UAS-Cdc42RNAi \\
\hline S7 & $\mathrm{D}, \mathrm{D}^{\prime}, \mathrm{H}, \mathrm{H}^{\prime}$ & Cdc42 FLPout RNAi & hsFLP;AyGal4-25b,UASredstingerNLS/UAS-Cdc42RNAi \\
\hline
\end{tabular}

